\title{
Factors determining spectral width of HF echoes from high latitudes
}

\author{
P. V. Ponomarenko, C. L. Waters, and F. W. Menk \\ University of Newcastle, Callaghan, New South Wales, Australia
}

Received: 15 December 2006 - Revised: 27 February 2007 - Accepted: 15 March 2007 - Published: 29 March 2007

\begin{abstract}
Spectral width is one of the standard data types produced by the Super Dual Auroral Radar Network (SuperDARN). A pronounced latitudinal gradient in spectral width has been reported in the literature and is used as an empirical proxy for the ionospheric footprint of the open-closed field-line boundary. In this work we investigated the daytime radar echo properties near the spectral width boundary using a multi-frequency sounding regime. We have found that the relatively large spectral width values $\geq 150 \mathrm{~m} / \mathrm{s}$ observed poleward of the boundary are produced by ionospheric irregularities with lifetime $\tau_{l} \simeq 10-25 \mathrm{~ms}$, which is essentially independent of the scale size. These irregularities are statistically co-located with low-energy $(\sim 100 \mathrm{eV})$ electron precipitation, which may play a major role in producing F-region turbulence above 75 MLAT via restructuring the ionospheric plasma on time scales $\sim \tau_{l}$.
\end{abstract}

Keywords. Ionosphere (Ionospheric irregularities; Particle precipitation) - Magnetospheric physics (Magnetosphereionosphere interactions)

\section{Introduction}

The Super Dual Auroral Radar Network (SuperDARN) (Greenwald et al., 1995) produces data that are used to map 2-D ionospheric plasma convection over the high-latitude regions using line-of-sight Doppler velocities, $V_{D}$, measured by pairs of HF radars with overlapping fields of view. To achieve the required spatial coverage $(\sim 3500 \mathrm{~km})$ and Doppler velocity range $\left(\left|V_{D}\right| \leq 2 \mathrm{~km} / \mathrm{s}\right)$, SuperDARN radars measure complex autocorrelation functions (ACF) of the echoes using a sequence of non-evenly separated transmitter pulses (Greenwald et al., 1985; Baker et al., 1995; Ponomarenko and Waters, 2006). The gradient of the ACF phase

Correspondence to: P. V. Ponomarenko

(phpp@alinga.newcastle.edu.au) with time lag is used to estimate $V_{D}$. The other parameter regularly used for diagnostic purposes is spectral width, $W$, calculated from the decay time of the ACF power (Baker et al., 1995; Ponomarenko and Waters, 2006). It is conventionally represented in velocity units, assuming that the spectral broadening is caused by plasma drifts. The spectral width is found to show maximum values $\geq 300 \mathrm{~m} / \mathrm{s}$ around the cusp (Baker et al., 1995) and to regularly exhibit a socalled spectral width boundary (SWB), which represents an increase from below to above $150-200 \mathrm{~m} / \mathrm{s}$ with increasing corrected geomagnetic latitude (MLAT) (e.g. Chisham et al., 2004, 2005a,b). It has been suggested that the SWB might represent an ionospheric projection of some magnetospheric boundaries, and extensive statistical studies by Chisham et al. (2004, 2005b) revealed a close relation between the SWB and the open-closed field-line boundary (OCB) measured via particle data from DMSP satellites. As a result, the SWB is routinely used as an empirical proxy of the OCB over most of magnetic local time (MLT).

While a number of mechanisms were proposed to explain the processes producing the SWB, including both physical phenomena and data processing artefacts (e.g. Hanuise et al., 1993; Baker et al., 1995; André et al., 2000; Moen et al., 2001; Parkinson et al., 2004; Chisham et al., 2005b), they generally failed to satisfactory explain the whole set of experimental results, including the existence of large spectral width values, $W \geq 200 \mathrm{~m} / \mathrm{s}$. Recently, Ponomarenko and Waters (2006) revised the software package FITACF used for processing the SuperDARN data and found that the software produces $W$ values that are generally overestimated by 20 $40 \%$. Applying a revised FITACF package to a selected interval of night-time data, Ponomarenko and Waters (2006) re-evaluated previously proposed mechanisms for large $W$ and found that the corrected experimental estimates of $W$ are close to theoretical values predicted by Bohm diffusion considered by André et al. (2000). However, as we show later, even the revised FITACF algorithms produce a statistically

Published by Copernicus GmbH on behalf of the European Geosciences Union. 


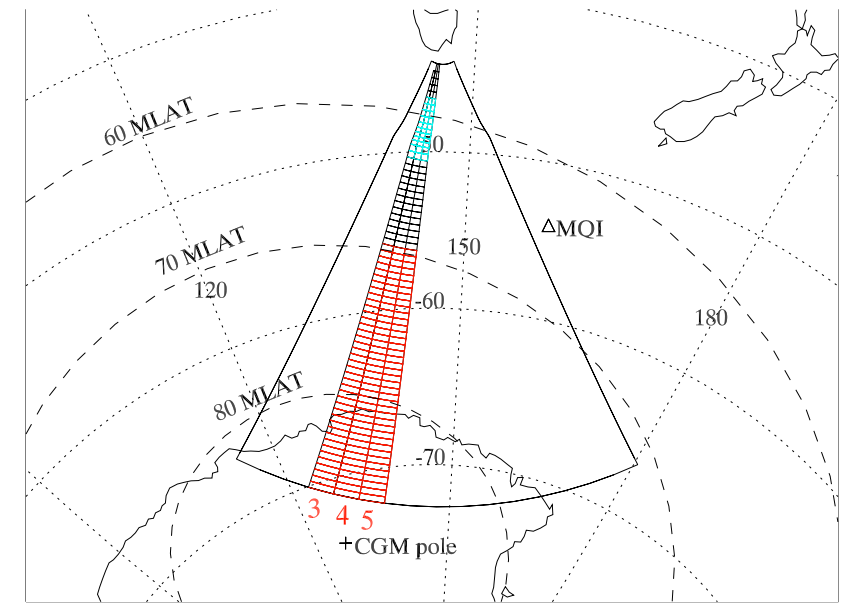

Fig. 1. TIGER beams 3, 4 and 5 used in this paper (mesh area). Dotted and dashed lines correspond to geographic and AACGM coordinates, respectively. Red- and cyan-coloured area shows respective range spans for $\mathrm{F}$ (gates 30-70) and E-region (gates 5-15) echoes analysed in this paper. Beam numbers are shown in red.

significant number of spectral width values exceeding the upper theoretical limit for Bohm diffusion leaving the problem of the large $W$ largely unresolved.

Moreover, some other important experimental facts are still unexplained. Any diffusion mechanism, including Bohm's, predicts increasing $W$ with radar frequency $f_{0}$, but in reality Vallières et al. (2003) observed the exact opposite, i.e. decreasing $W$ with increasing $f_{0}$. Vallières et al. (2004) attempted to explain the observed effect via distortion of the wavefront due to forward scatter of the radar signal by largescale ionospheric irregularities. However, while attempting to interpret the observed difference in $W$ the authors did not explain the existence of echoes with $W \geq 200 \mathrm{~m} / \mathrm{s}$.

Several studies have hinted at a close relationship between $W$ and particle precipitation (Baker et al., 1986, 1990; Dudeney et al., 1998; Lester et al., 2001; Moen et al., 2001, 2002; Woodfield et al., 2002; Chisham et al., 2005a). Moen et al. $(2001,2002)$ demonstrated that the dayside OCB coincides with the equatorward boundary of $630 \mathrm{~nm}$ optical emission caused by "soft" electron precipitation. Recently, Chisham et al. (2005a) concluded that the magnitude of $W$ shows anti-correlation with the total electron energy flux, but no explanation of these relationships has been provided.

Finally, following Hanuise et al. (1993) and Villain et al. (1996), Ponomarenko and Waters (2006) pointed out that the exponential decay typically observed in large- $W$ ACFs argues for the characteristic lifetime of irregularities, $\tau_{l}$, as a major factor determining $W$. The random drifts generally leading to the Gaussian decay are unlikely to have a decisive effect. Thus, it might be misleading to represent $W$ in velocity units, and it is more appropriate to describe these echoes in terms of the ACF decay time, $\tau_{c} \simeq W /(\lambda / 2)$.
In this work we investigated the origin of the SWB by addressing two major issues: (i) the fact that $W$ decreases with increasing radar frequency, $f_{0}$ (Vallières et al., 2003) and (ii) complex relations between $W$ and precipitating particles (Chisham et al., 2005b). In pursuing the above objectives, we (i) reproduce measurements of $W\left(f_{0}\right)$ by Vallières et al. (2003) using the revised version of FITACF (Ponomarenko and Waters, 2006), (ii) abandon the assumption of a velocityrelated mechanism for spectral broadening and (iii) analyse the relationship between $W$ and differential electron flux in different energy bands.

\section{Experimental setup}

The investigation of $W$ as a function of radar frequency required multi-frequency sounding of the high-latitude irregularities. A special mode campaign was run on the $\mathrm{Su}-$ perDARN TIGER radar (Tasmania) between 00:00 UT 2 September and 08:00 UT 6 September 2005. The radar was operated in a three-beam mode using beams 3, 4 and 5 (mesh area in Fig. 1) sampled consecutively at probing frequencies $f_{0} \simeq 9.9,11.5$ and $13.5 \mathrm{MHz}$, respectively, with the standard integration time $\simeq 7 \mathrm{~s} /$ beam (sampling rate $\simeq 21 \mathrm{~s}$ ). The central beam, $\# 4$, is approximately aligned with $\simeq 226^{\circ}$ of the altitude adjusted corrected geomagnetic (AACGM, Baker and Wing, 1989) longitude (MLT noon $\simeq 01: 30$ UT), with the other two beams shifted by $\simeq \pm 3^{\circ}$ in azimuth. The radar output parameters were estimated using the revised FITACF data processing package, which allows for more accurate estimate of $W$ (for details see Ponomarenko and Waters, 2006).

According to the data from the ACE satellite located in the vicinity of the libration point at $\simeq 230 R_{E}$ sunward from the Earth, during the campaign the average solar wind (SW) and interplanetary magnetic field (IMF) parameters were $B_{x}=-3.6 \pm 2.3 \mathrm{nT}, \quad B_{y}=2.0 \pm 3.1 \mathrm{nT}$, $B_{z}=-0.9 \pm 3.4 \mathrm{nT}, \quad B_{\mathrm{tot}}=6.5 \pm 2.5 \mathrm{nT}, \quad n_{p}=3.8 \pm 2.6 \mathrm{~cm}^{-3}$, and $V_{s w}=568 \pm 98 \mathrm{~km} / \mathrm{s}$, where $B_{x}, B_{y}, B_{z}$ and $B_{\text {tot }}$ are the GSM components and magnitude of the IMF, respectively, while $n_{p}$ is the proton density and $V_{s w}$ is the SW velocity. Particle precipitation was monitored using data from the SSJ4/5 sensors onboard the DMSP series satellites available on-line from the JHU/APL website http://sd-www.jhuapl.edu/Aurora/dataset_list.html.

\section{Case study}

In Figs. 2 and 3 we present a 24-h example of the special mode data starting at 20:00 UT 2 September 2005. The MLT noon and midnight are marked by vertical red lines, while the AACGM latitude is shown on the right axis by the outward tick marks. The large- $W$ echoes first appear at $\simeq 22: 00$ UT $(\simeq 08: 30$ MLT) between gates $45-60$ $(\simeq 77-85$ MLAT $)$ and after 01:00 UT (11:30 MLT) move equatorward and transform into the lower- $W$ component 

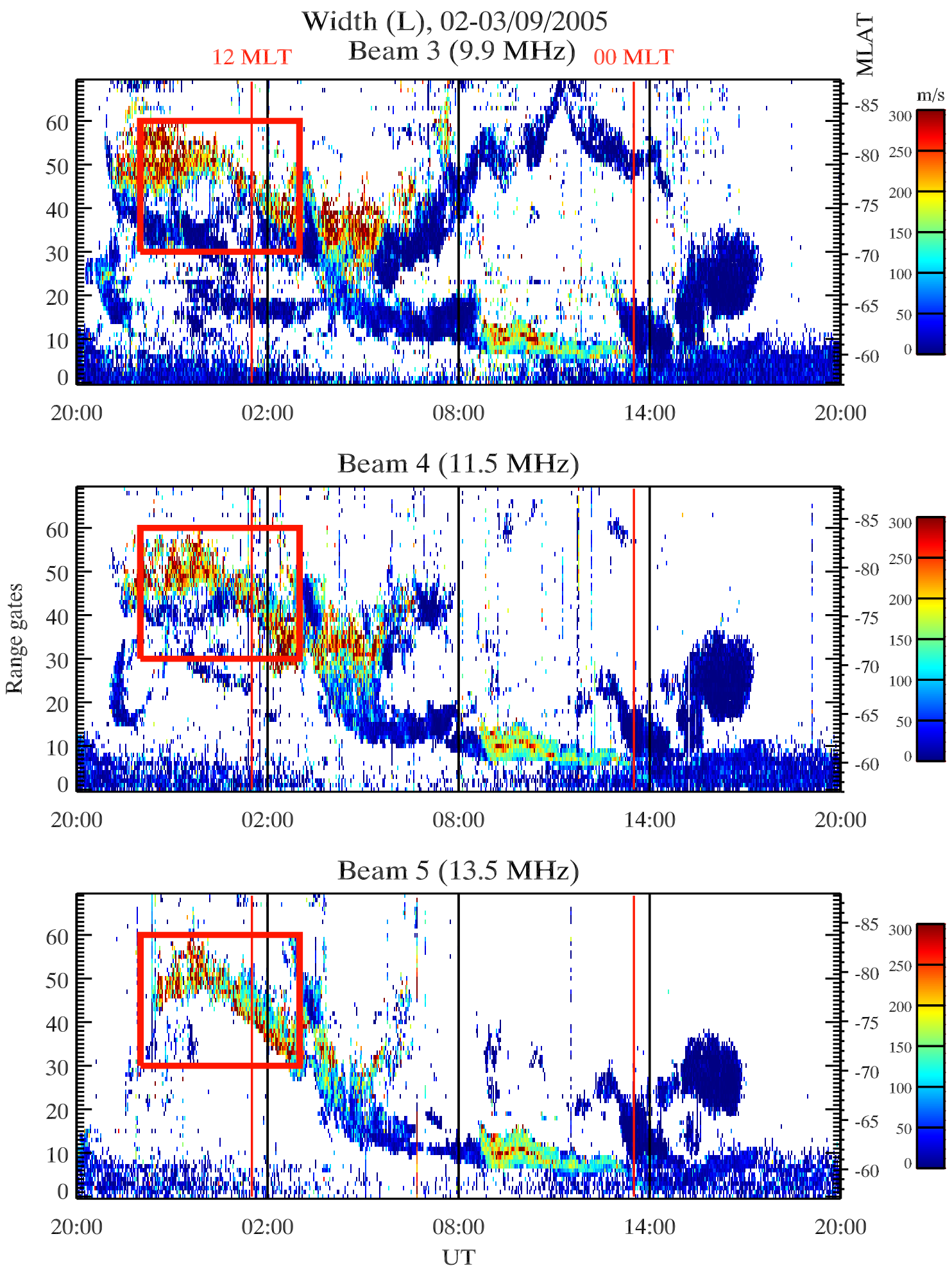

Fig. 2. Example range-time map of TIGER spectral width data during the multi-frequency experiments in September 2005. Probe frequency increases from top to bottom. The red rectangle encloses large- $W$ F-region scatter data anlysed later in this section.

below gate 30 (70 MLAT) between 04:00-06:00 UT (14:3016:30 MLT). The E-region scatter component is promi- nent in all three beams during 09:00-14:00 UT $(\sim 19: 30-$ 01:30 MLT) around gate 10 ( $\simeq 62$ MLAT). There are also 

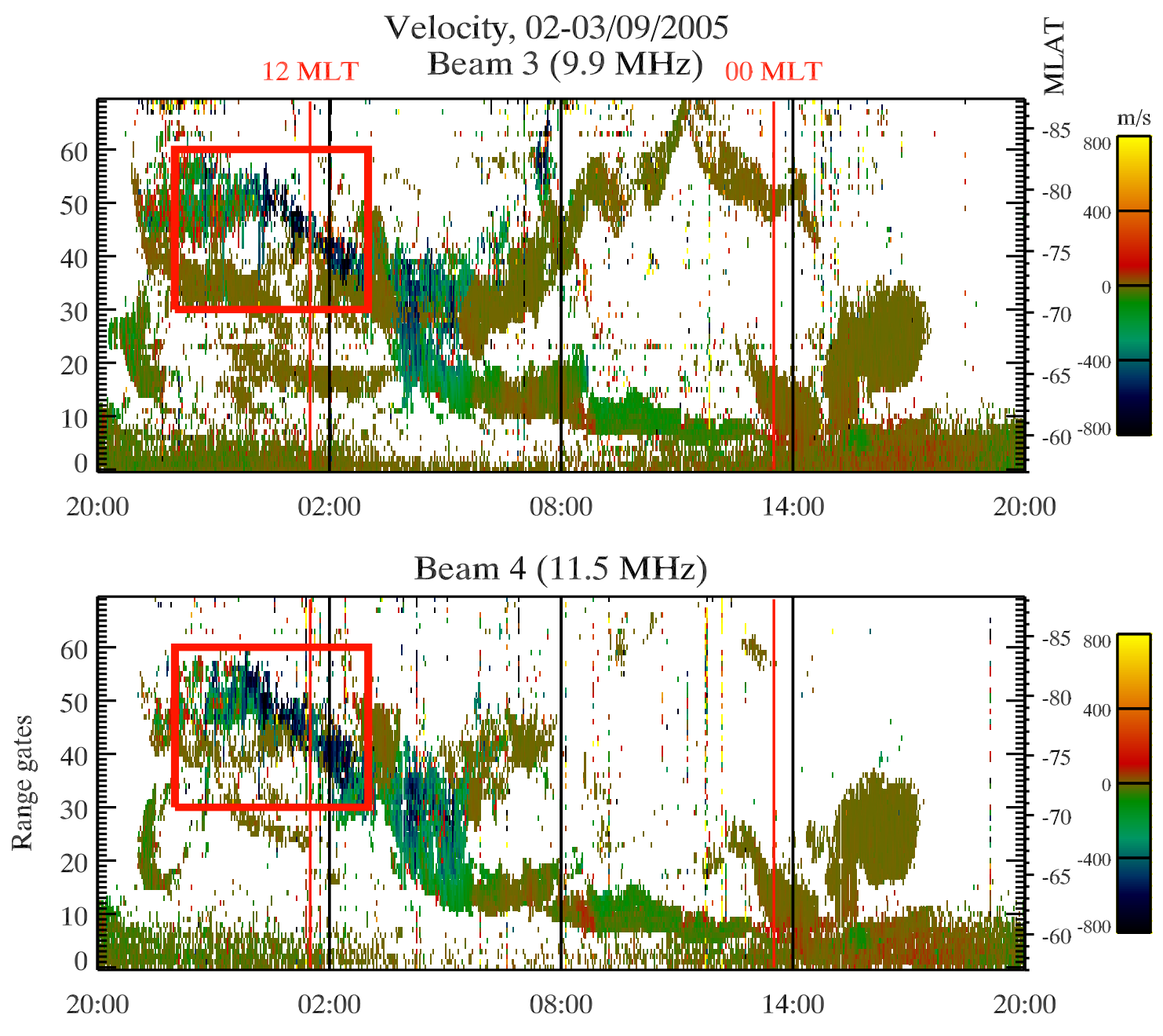

Beam $5(13.5 \mathrm{MHz})$

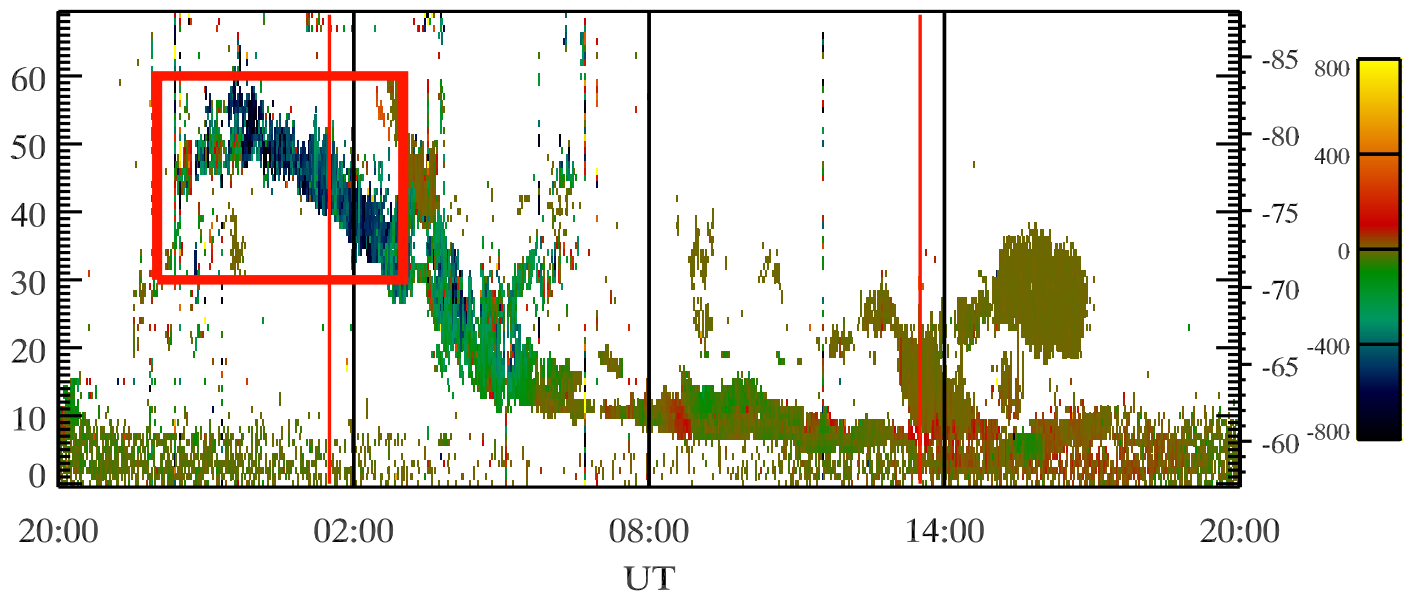

Fig. 3. The same as in Fig. 2 but for line-of-sight velocity.

low- $W$ sea-scatter echoes, which are most visible at the lowest probe frequency, $f_{0}=9.9 \mathrm{MHz}$ (top panel), and the low$W$ ionospheric returns from below gate 30 observed by all three beams around 13:00-17:00 UT. The sporadic closerange echoes from gates 1-10 can probably be attributed to meteor scatter, but this requires further clarification. 
02-03 September 2005, 22:00-03:00UT, gates 30:60

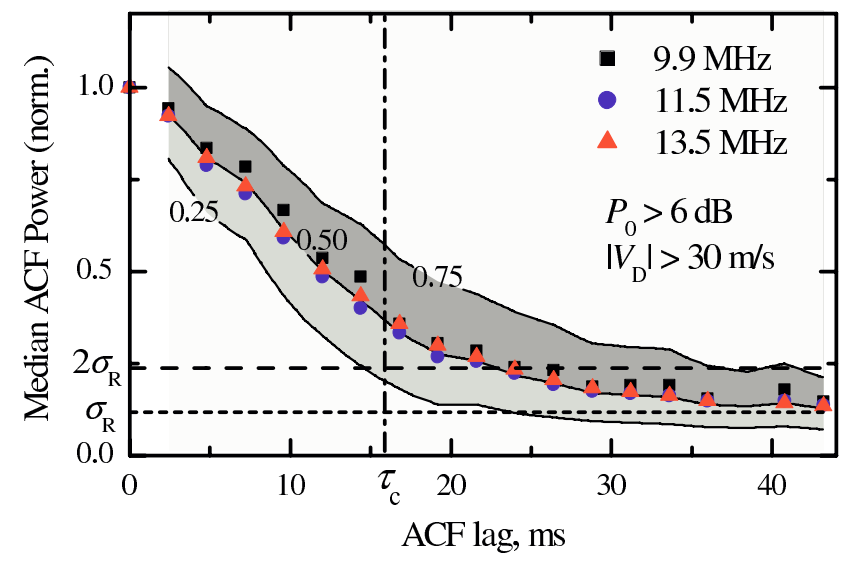

Fig. 4. Median normalized ACF power for the F-region scatter data identified by the red rectangle in Fig. 2 (squares, circles and triangles). All three frequencies exhibit very similar quasi-exponential shapes with $e$-fold decay time $\tau_{c} \simeq 16 \mathrm{~ms}$. Grey-scale contours correspond to first, second and third quartiles of the overall three-beam distribution at each ACF lag. Horizontal dotted line shows statistical fluctuation level, $\sigma_{R}=1 / \sqrt{N_{\mathrm{avg}}}$, where $N_{\mathrm{avg}}=78$, the number of averaged pulse sequences used to obtain a single ACF. Further details on the significance of $\sigma_{R}$ are provided by Ponomarenko and Waters (2006).

Importantly, in contrast to the night time records from Ponomarenko and Waters (2006), which were effectively restricted to the theoretical threshold for the Bohm diffusion (André et al., 2000), $W \simeq 200 \mathrm{~m} / \mathrm{s}$, the daytime F-region scatter in Fig. 2 show a significant percentage of echoes with $W$ well above this limit leaving the origin of the spectral broadening unidentified.

In order to analyse the dependence of large- $W$ echoes on the radar frequency $f_{0}$, we selected a range-time interval between 22:00-03:00 UT and gates 30-60 (red rectangle in Figs. 2-3), when the ionospheric scatter was continuously observed at all three probe frequencies. Since the ionospheric echoes from these ranges exhibit relatively high velocities (Fig. 3), to remove the remaining sea-scatter returns in beams 3 and 4 we restricted our data to $\left|V_{D}\right|>30 \mathrm{~m} / \mathrm{s}$. Finally, to minimize the contribution from external noise, the scatter power (signal-to-noise ratio) was chosen at $P_{0} \geq 6 \mathrm{~dB}$.

In searching for causes of spectral broadening it is important to start the analysis from the original ACF data to avoid any bias due to data processing artefacts and initial assumptions about ACF shape. In Fig. 4 we show median normalized ACF power versus time lag for all three radar frequencies. At this stage we excluded only lags affected by transmitter pulse overlap and cross-range interference (Ponomarenko and Waters, 2006). These median ACFs exhibit remarkably similar quasi-exponential shapes at all three frequencies with $e$-fold correlation time scale, $\tau_{c} \simeq 16 \mathrm{~ms}$. This similarity allowed an overplot of probability quartiles for
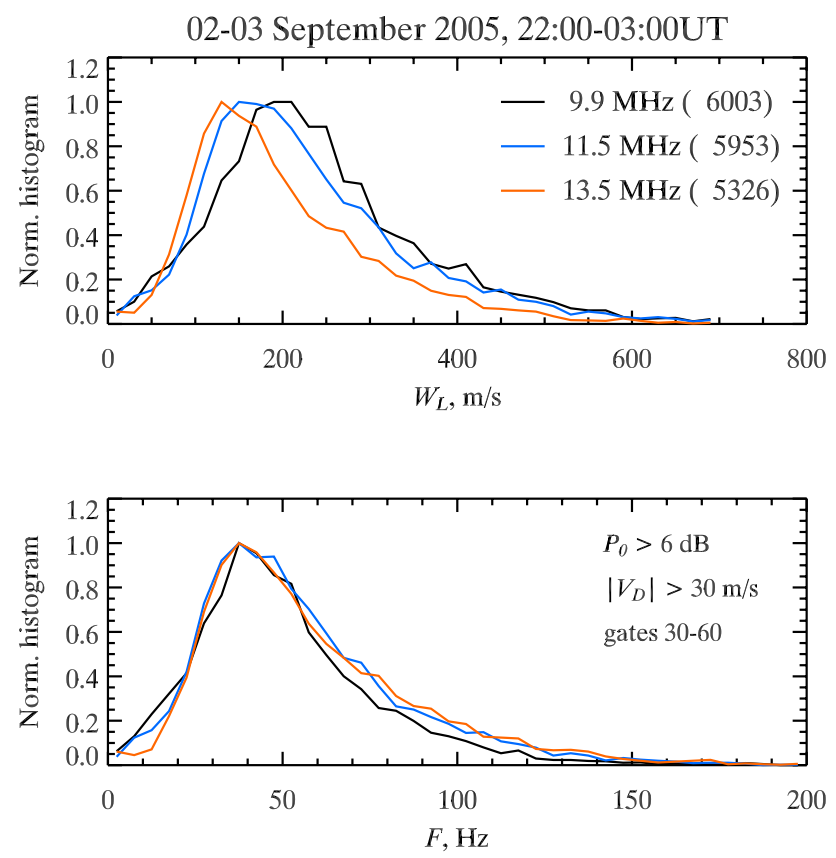

Fig. 5. Spectral width histograms for the data enclosed by the red rectangles in Figs. 2-3. The top panel presents width measured in $\mathrm{m} / \mathrm{s}, W$, while the bottom panel shows the same data but in $\mathrm{Hz}, F$. The numbers in brackets are respective numbers of processed ACFs for each radar frequency.

the overall three-frequency distribution of ACF power (greyscale contours). As expected, the median ACF power values lie close to the second quartile $(P \geq 0.5)$. The horizontal dotted line shows a theoretical statistical fluctuation level, $\sigma_{R}=R(0) / \sqrt{N_{\text {avg }}}$, used in FITACF as a lower ACF power cutoff, i.e. all lags with $|R(\tau)|<\sigma_{R}$ are effectively excluded from the fitting process (Ponomarenko and Waters, 2006). As shown in Fig. 4, the median power asymptotically approaches $\sigma_{R}$ above $\tau \simeq 35 \mathrm{~ms}$, where $|R(\tau)|$ has decorrelated. The value for $\sigma_{R}$ represents the mathematical expectation of the statistical fluctuation level. For $\tau_{c}>35 \mathrm{~ms}$ where the statistical fluctuations dominate, about $50 \%$ of the $|R(\tau)|$ values still exceed $\sigma_{R}$. Therefore, the use of $\sigma_{R}$ as the lower power cutoff produces an artificially long ACF "tail", which might distort resulting spectral width values. To correct this problem, we increased the cutoff magnitude to $2 \sigma_{R}$ (dashed line in Fig. 4) rejecting at least $75 \%$ of the statistical "noise". This change produced a relatively broader distribution for $W$, but the median $W$ did not change, and the total number of valid ACFs decreased by only 5\%. This figure also allowed us to estimate a range of the decay times, which we defined at an $e$-fold ACF power decay level for the first and third quartiles $(0.25 \leq P \leq 0.75)$ obtaining $\tau_{c} \simeq 10-25 \mathrm{~ms}$.

The spectral width histograms for the selected data are shown in Fig. 5 (top panel). These results are in agreement with Vallières et al. (2003), who also observed a noticeable 


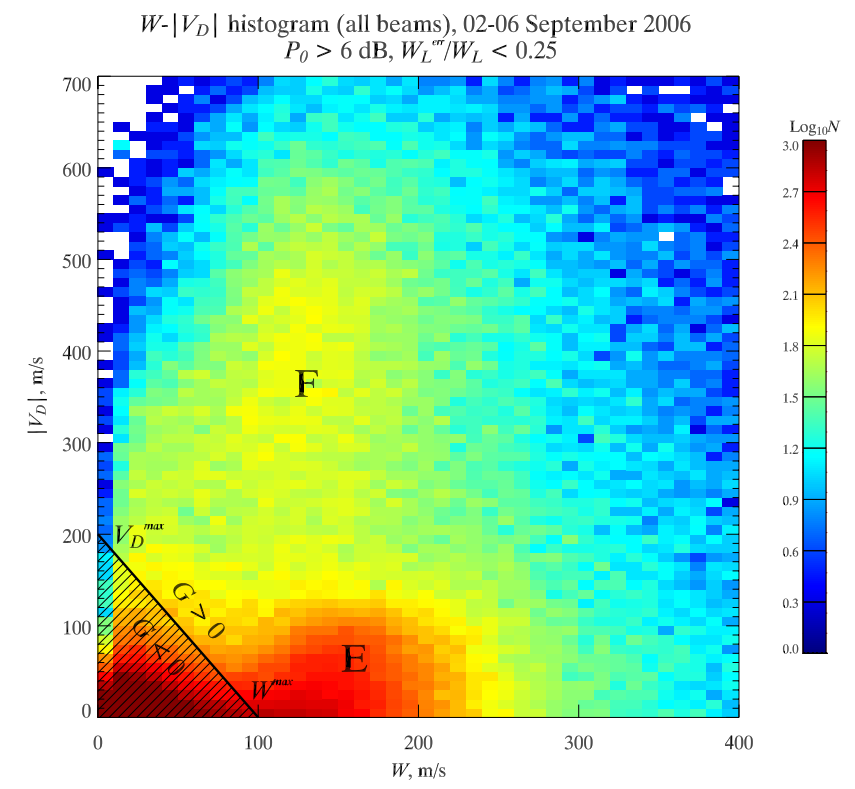

Fig. 6. Graphic illustration of the sea/mixed scatter rejection criterion used in this paper.

decrease in $W$ with increasing radar frequency. The spectral width is conventionally represented in meters per second based on the assumption that $W$ originates from the Doppler shifts caused by the drift velocity variations inside the scatter volume. However, the observed exponential ACF decay indicates that $W$ is determined by irregularity lifetime mechanisms (Hanuise et al., 1993; Villain et al., 1996; Ponomarenko and Waters, 2006). Therefore, the bottom panel in Fig. 5 shows distributions of the "normalized" spectral width, $\left.F=1 / \tau_{c} \simeq(W / c) f_{0}\right)$, measured in $\mathrm{Hz}$ instead of $\mathrm{m} / \mathrm{s}$. This representation is more suitable because we do not assume a drift-related origin of the spectral broadening. After this transformation, in agreement with Fig. 4, all three distributions become remarkably similar with their maxima located around $40 \mathrm{~Hz}$. Finally, the E-region scatter ACF power (not shown) also exhibited exponential shape similar to that for the F-region scatter, but, in contrast to F-region echoes, $\tau_{c}$ values decreased for larger $f_{0}$.

\section{Statistical studies}

In this section we statistically test the case study results described in the previous section. The analysis of many events required for a statistical study is facilitated by suitable computer algorithms. Routine processing of SuperDARN data can be challenging as there are usually many different physical effects with their associated signatures in a typical dataset. While the sea scatter component is relatively easy to remove based on the inherently low width and velocity values, $W, V_{D} \leq 30-60 \mathrm{~m} / \mathrm{s}$, mixed sea and ionospheric scatter is difficult to identify. In the previous section, to separate the mainly large- $V_{D}$ ionospheric scatter from low- $V_{D}$ sea-scatter echoes we rejected all returns with $\left|V_{D}\right| \leq 30 \mathrm{~m} / \mathrm{s}$. However, if applied to the whole dataset, this procedure would also remove the large- $W$ echoes with low line-of-sight velocities similar to E-region scatter at gates 5-15 during 09:0014:00 UT in Figs. 2-3. Therefore, we require a more sophisticated algorithm which is described below.

\subsection{Mixed scatter rejection criteria}

In the present SuperDARN software the definition of sea/ground scatter is based on the two-dimensional distribution of spectral width and velocity, $p\left(W,\left|V_{D}\right|\right)$. Figure 6 shows this distribution obtained for the whole September 2005 data campaign. To calculate $p\left(W,\left|V_{D}\right|\right)$, we used data from all three beams and restricted the ACFs to those with at least three valid lags, a signal-to-noise ratio, $P_{0} \geq 6 \mathrm{~dB}$, and normalized Lorentzian width error $W_{L}^{\text {err }} / W_{L} \leq 0.25$. After analysing range-time diagrams for $V_{D}$ and $W$ we found that the echoes with $\left|V_{D}\right| \geq 200 \mathrm{~m} / \mathrm{s}$ represent the large- $W$ F-region scatter (capital $\mathrm{F}$ in Fig. 6), the low-velocity enhancement across $W=100-200 \mathrm{~m} / \mathrm{s}$ describes E-region scatter (capital E), and the third component with $W \leq 100 \mathrm{~m} / \mathrm{s}$ and $V_{D} \leq 200 \mathrm{~m} / \mathrm{s}$ consists predominantly of sea- and mixed scatter echoes. To eliminate the mixed scatter, we applied the empirical procedure originally developed by $\mathrm{G}$. T. Blanchard and K. Baker (private communication), for detecting ground scatter echoes. The procedure is based on the experimental fact that the sea/ground scatter echoes are usually restricted to a triangular area in the $\left(W,\left|V_{D}\right|\right)$ domain with corners positioned at $(0,0),\left(W^{\mathrm{max}}, 0\right)$ and $\left(0, V_{D}^{\max }\right)$. The algorithm relies on a parameter

$G=\left|V_{D}\right|-V_{D}^{\max }\left(1-|W| / W^{\max }\right)$,

where Blanchard and Baker used $V_{D}^{\max }=30 \mathrm{~m} / \mathrm{s}$, $W^{\max }=90 \mathrm{~m} / \mathrm{s}$. The echoes with $G \leq 0$ (i.e. confined to the triangular area) are considered to be ground/sea scatter. For our data shown in Fig. 6, the mixed scatter component is also limited to a quasi-triangular area, which allows us to apply the above procedure but with expanded cutoffs, $V_{D}^{\max }=200 \mathrm{~m} / \mathrm{s}$ and $W^{\max }=100 \mathrm{~m} / \mathrm{s}$. The rejected echoes are shown by diagonal shading. To demonstrate the effectiveness of our selection criteria, in Fig. 7 we presented the same data as in Fig. 2 but after applying the above algorithm. They show essentially the same general pattern for all radar frequencies although with relatively minor variations, which might be attributed to differences in ionospheric propagation conditions for different $f_{0}$. The pattern presented in Fig. 7 was generally repeated with minor changes from day to day during the whole campaign 2-6 September 2005.

\subsection{Experimental results}

To ensure that the decrease of spectral width with increasing probe frequency observed in the case study is representative of the data, we statistically processed records from 

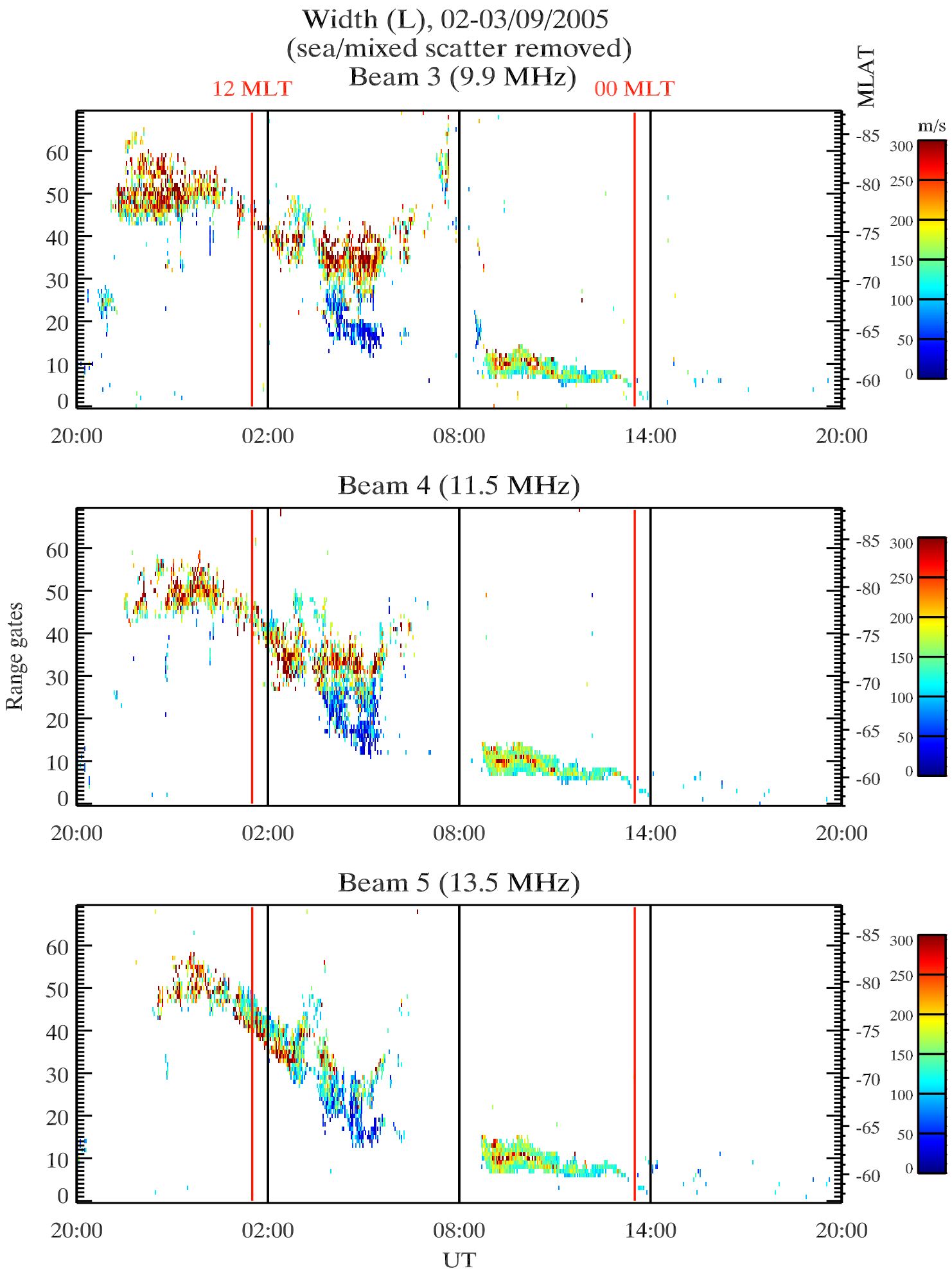

Fig. 7. The same as in Fig. 2 but with sea/mixed scatter removed (see text for details).

the whole September 2005 campaign after rejecting sea and mixed scatter echoes. In Fig. 8 we present 2-D $W$ range histograms for three radar frequencies. The horizon- tal dashed lines mark range gates affected by transmitter pulses coinciding in time with the scatter echoes resulting in a lower number of valid echoes. This effect produces 

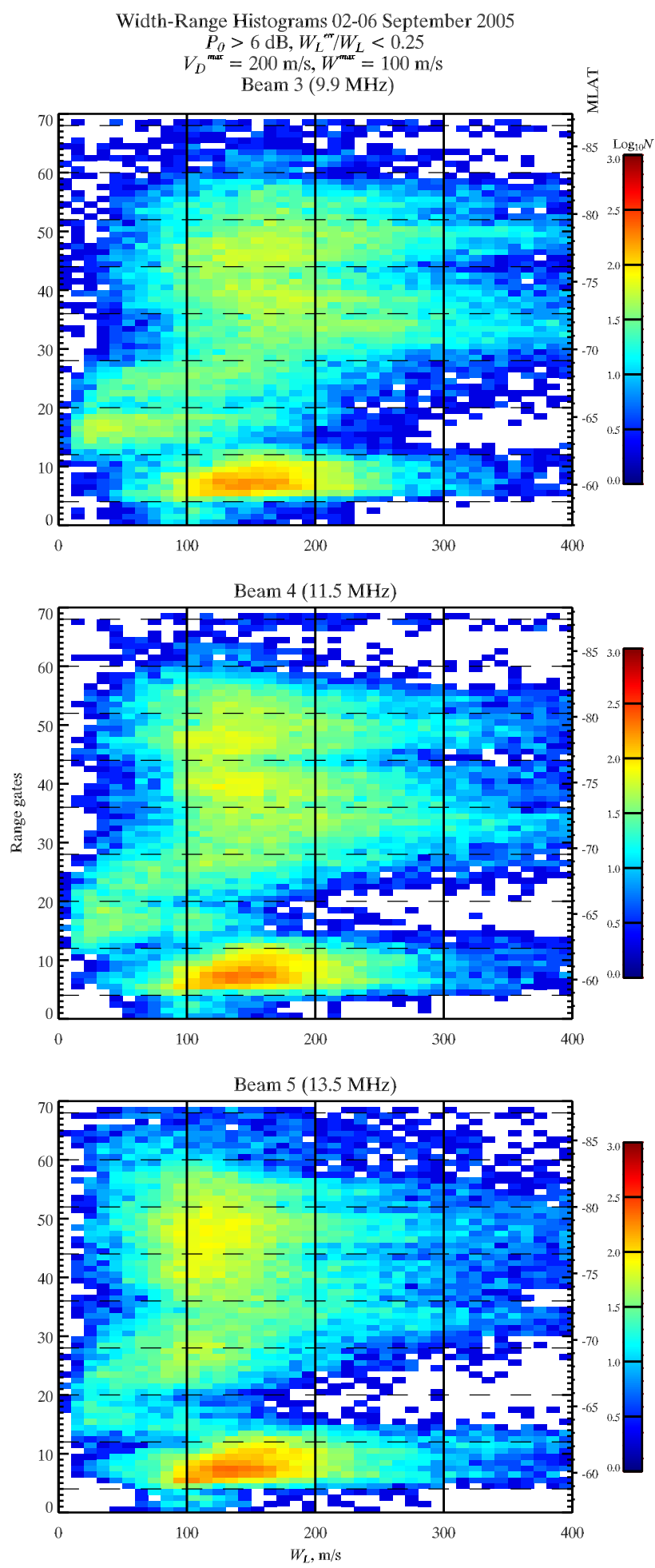

Fig. 8. Spectral width-range gate histograms for 2-6 September 2005.

artificial latitudinal data "gaps", which are particularly apparent around gates 20 and 44. The histograms in Fig. 8 exhibit three distinct components: (i) high-latitude F-region scatter
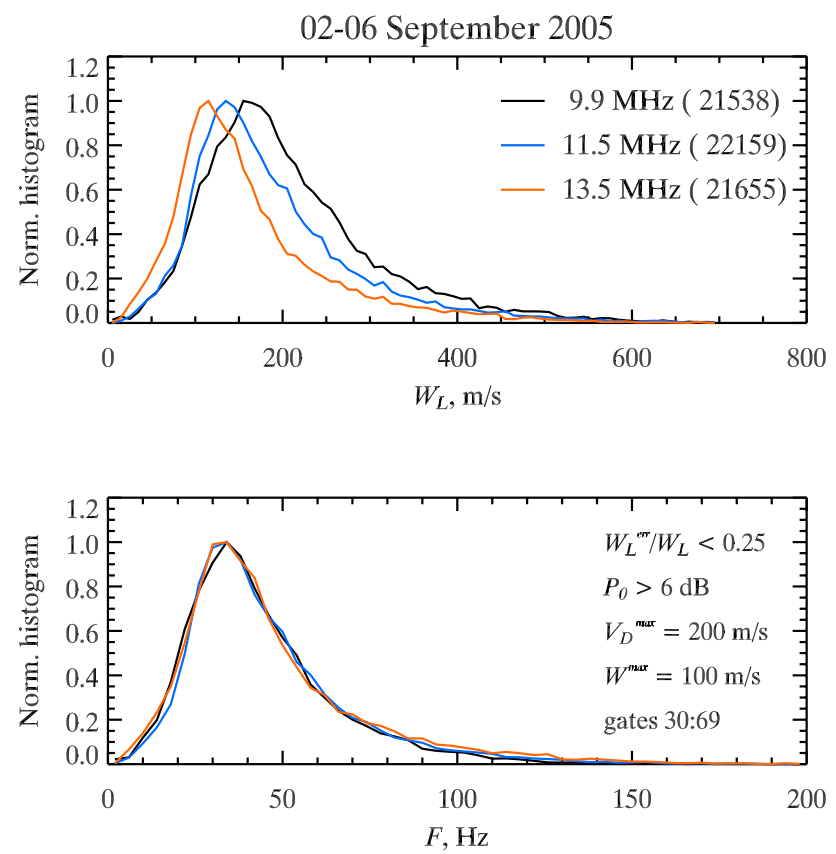

Fig. 9. Normalized F-region scatter histograms $\left(\mathrm{MLAT} \geq 70^{\circ}\right)$ for 2-6 September 2005.

(gates 30-70, MLAT $\geq 70^{\circ}$ ), (ii) E-region scatter (gates 5$15, \operatorname{MLAT} \simeq 58-63^{\circ}$ ) and (iii) intermediate F-region scatter between gates $20-30\left(\right.$ MLAT $\left.\simeq 66-70^{\circ}\right)$, where the transition from high to relatively low spectral width is observed. Our particular interest lies with the first component, which corresponds to the large- $W$, F-region scatter echoes. This distribution noticeably shifts towards smaller $W$ with increasing radar frequency, in agreement with Vallières et al. (2003) and our case study. This effect is illustrated quantitatively in Fig. 9, which shows the average histograms in the same format as Fig. 5. In contrast to the F-region scatter component, the E-region echoes show the opposite trend: the $W$ distribution does not change with $f_{0}$, while the "normalized" spectral width values represented in Hertz, $F$, increase with $f_{0}$ (Fig. 10).

\section{Discussion}

According to the collective scatter theory, the major contribution to the backscattered field at the radar site is given by random arrays of irregularities with a line-of-sight (LOS) spatial period satisfying the Wulf-Bragg condition, $l=\lambda / 2$, where $\lambda$ is a radar wavelength (Rytov et al., 1988). The spectral width of the scattered field is inversely proportional to its correlation time scale $F \simeq 1 / \tau_{c}$. The latter is affected by two major factors: (i) lifetime of the random resonant arrays of the irregularities, $\tau_{\text {arr }}$ (Rytov et al., 1988; Hanuise et al., 1993; Villain et al., 1996) and (ii) geometrical effect of the large-scale drifts, which is proportional to the difference in the LOS 
direction within the scatter volume (e.g Rytov et al., 1988; Ponomarenko and Waters, 2003). For SuperDARN radars, the scatter volume dimensions are small compared with the distance to the radar so the expected broadening due to geometrical effects is considerably smaller than the experimentally observed spectral width (e.g. Ponomarenko and Waters, 2003). In this situation the major contribution to spectral broadening is due to the finite lifetime of the random arrays, which determines the measured correlation time scale of the scattered signal, $\tau_{c}=\tau_{\text {arr }}$. The lifetime is limited by two factors: (i) random drifts of individual irregularities characterized by the average velocity fluctuation magnitude, $\delta v$, and (ii) the finite lifetime of the Bragg-size irregularities, $\tau_{l}$. If $\tau_{l} \rightarrow \infty$ and $\delta v \neq 0$, then the phasing is effectively destroyed after an average irregularity randomly travels over the resonant spatial period, $\lambda / 2$, and $\tau_{\mathrm{arr}}=\tau_{v}=\delta v /(\lambda / 2)$. This is a separate mechanism from the regular drift of the whole plasma volume. When $\tau_{l}$ is finite and $\delta v \rightarrow 0$, we will have $\tau_{\text {arr }} \simeq \tau_{l}$. In reality, the fastest process determines $\tau_{c}$.

This theoretical approach was applied to the SuperDARN echoes by Hanuise et al. (1993) and Villain et al. (1996), whose model was based on a combination of random plasma drift ("wandering irregularities") and plasma diffusion (lifetime) as factors determining spectral width. Their analysis showed that a Gaussian function best describes the average ACF power with lag if the random drift processes prevail. When diffusion processes dominate, an exponential function describes the ACF power regardless of the particular decay law for an individual irregularity.

As previously reported (e.g. Hanuise et al., 1993) and illustrated by our Fig. 4, the majority of experimental ACFs with $W \geq 100-150 \mathrm{~m} / \mathrm{s}$ are best described by the exponential model, which argues for the lifetime processes playing a major role in the observed spectral broadening. Any diffusion process will lead to an increase in $W$ with increasing $f_{0}$ because smaller irregularities should decay quicker, $\tau_{l} \propto(\lambda / 2)^{2}$, and $W \simeq \lambda / 2 \tau_{l} \propto f_{0}$ (Hanuise et al., 1993; Villain et al., 1996; Ponomarenko and Waters, 2006). However, our results show that the F-region irregularity lifetime is independent of scale size (Fig. 4), so diffusion cannot be the major factor forming large $W$.

A possible explanation for this is that irregularities of all sizes, at least within the decameter range, are being recreated by the same source on a time scale $\tau_{l} \sim 10-25 \mathrm{~ms}$. This time scale may be just too short for the diffusion processes to manifest themselves at different scale sizes since the ambipolar diffusion time constant for the F-region decameter irregularities is $\sim 1 \mathrm{~s}$ (e.g. Ponomarenko and Waters, 2003).

A feasible candidate for the generation mechanism might be particle precipitation, which exhibits a close but still poorly understood relationship with $W$ (Dudeney et al., 1998; Lester et al., 2001; Moen et al., 2001, 2002; Woodfield et al., 2002; Chisham et al., 2005a). Based on the observed co-location of the equatorward boundary for $630 \mathrm{~nm}$ emis-
02-06 September 2005
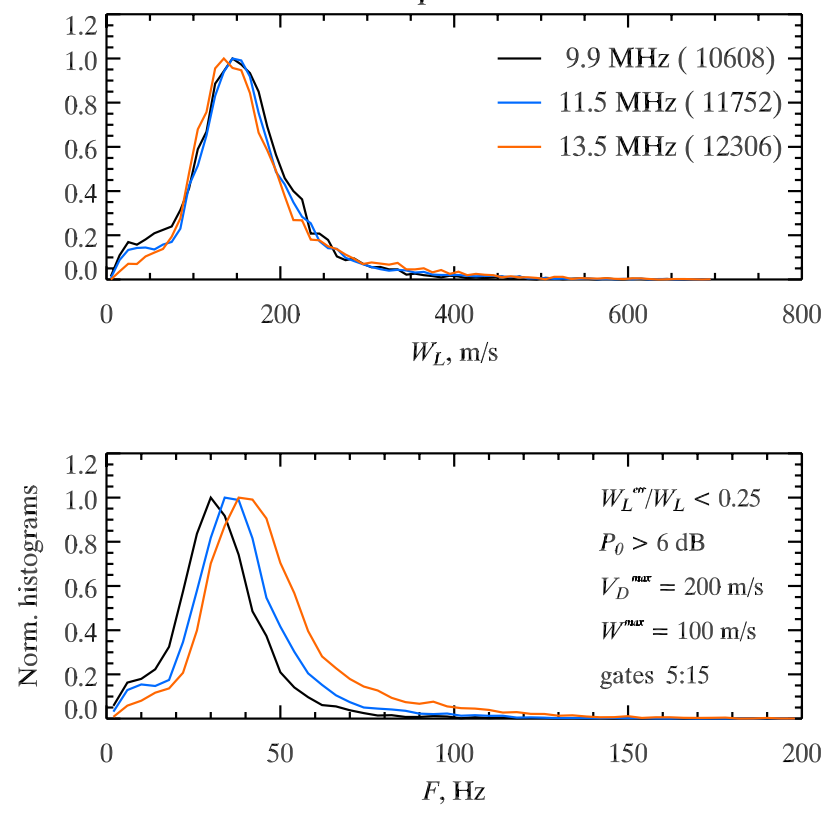

Fig. 10. Normalized E-scatter (gates 5-15) histograms for 2-6 September 2005.

sion and the SWB, Moen et al. (2001) suggested that particle precipitation can be structured on the decameter scale providing effective targets for HF radiowaves. Chisham et al. (2005a) concluded that $W$ is anti-correlated with total energy flux of precipitating particles. However, Villain et al. (2002) pointed out that electrons with energies $E_{e} \geq 1 \mathrm{keV}$ are generally absorbed in the lower ionosphere ( $\mathrm{E}$ and $\mathrm{D}$ regions), while those with $E_{e} \leq 200 \mathrm{eV}$ deposit their energy into the F-region, i.e. they might have a direct impact on the decameter plasma irregularities. Thus, it is probably more reasonable to analyse the correlation between $W$ and the low-energy population of precipitating electrons. For this purpose, we compare TIGER spectral width with the particle data from DMSP15 satellite in Fig. 11. The data were recorded at $\sim 22: 32-42$ UT on 4 September 2005, when the satellite was passing polewards directly above the TIGER field-of-view (thick blue line) at an altitude of $\sim 800 \mathrm{~km}$. We show the logarithm of differential electron energy flux, $J$, for $E_{e} \simeq 100 \mathrm{eV}$ and $\simeq 10 \mathrm{keV}$ by green and red areas, respectively. To emphasize the difference between these two components of the electron energy spectrum, we have plotted respective energy fluxes increasing in opposite directions from the baseline (satellite orbit). The lower cutoff for $J$ in this figure was arbitrarily chosen at $2 \times 10^{6} \mathrm{eV} / \mathrm{sr} \mathrm{m}^{2} \mathrm{~s} \mathrm{eV}$. While the green area characterizes the "soft" electrons directly affecting the F-region, the red closely resembles total energy flux analysed by Chisham et al. (2005a). The radar data were averaged over the time when the satellite was directly above the radar field-of-view ( $\simeq 9 \mathrm{~min}$ ), and the DMSP data were 
F15, 2005/09/04, 22:33:41-22:42:45UT

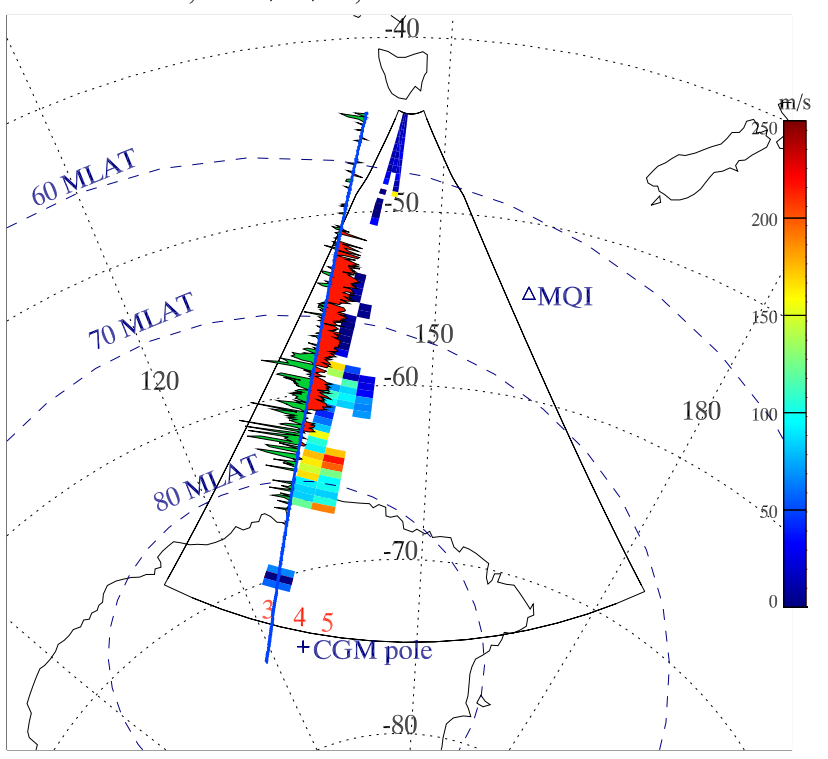

Fig. 11. Overpass of DMSP15 over TIGER filed of view on 4 September 2005.

sampled at $1 \mathrm{~s}$ rate. The respective time series are shown in Fig. 12 emphasizing the coincidence between the increase in $W$ and intensification of the low-energy electron precipitation, while the high-energy electrons show no obvious effect on the spectral width.

The case study shown in Fig. 11 has been compared with a statistical analysis. The median spectral width (TIGER) and electron flux data (DMSP13,15 and 16) calculated for the whole experimental campaign are presented as MLAT-MLT histograms in Figs. 13-15. The satellite data were averaged for both hemispheres assuming that around equinox the precipitation electron patterns are generally symmetric. Taking into account that for MLAT $\geq 70^{\circ}$ the decay time, $\tau_{c}$, is independent on the radar frequency, $f_{0}$, we "re-normalized" the spectral width data to the same apparent frequency $f_{0}=11.5 \mathrm{MHz}$. In these histograms we show only MLATMLT bins containing at least 100 data points. While the gaps in the radar data are caused by a lack of ionospheric returns, those in the DMSP database are mainly due to the limited coverage of MLT-MLAT by the sun-synchronous DMSP satellites. The $10-\mathrm{keV}$ electron distribution effectively duplicates that of total electron energy flux (not shown). In agreement with Figs. 11-12, it appears that the relatively large spectral width $W \geq 100-150 \mathrm{~m} / \mathrm{s}$ are related to the lowenergy electrons with $J \geq 1 \times 10^{6} \mathrm{eV} / \mathrm{sr} \mathrm{m}^{2} \mathrm{seV}$ rather than being anti-correlated with the high-energy particles. This is emphasized by the fact that the pronounced SWB around 66-67 MLAT and 14:00-20:00 MLT is not accompanied by a similar change in $J$ for the $10-\mathrm{keV}$ electrons, as suggested by Chisham et al. (2005a). More definite conclusions would require more rigorous statistical analyses involving extensive datasets with better MLT-MLAT coverage.
TIGER and F15, 22:33-22:42UT, 04/09/2005
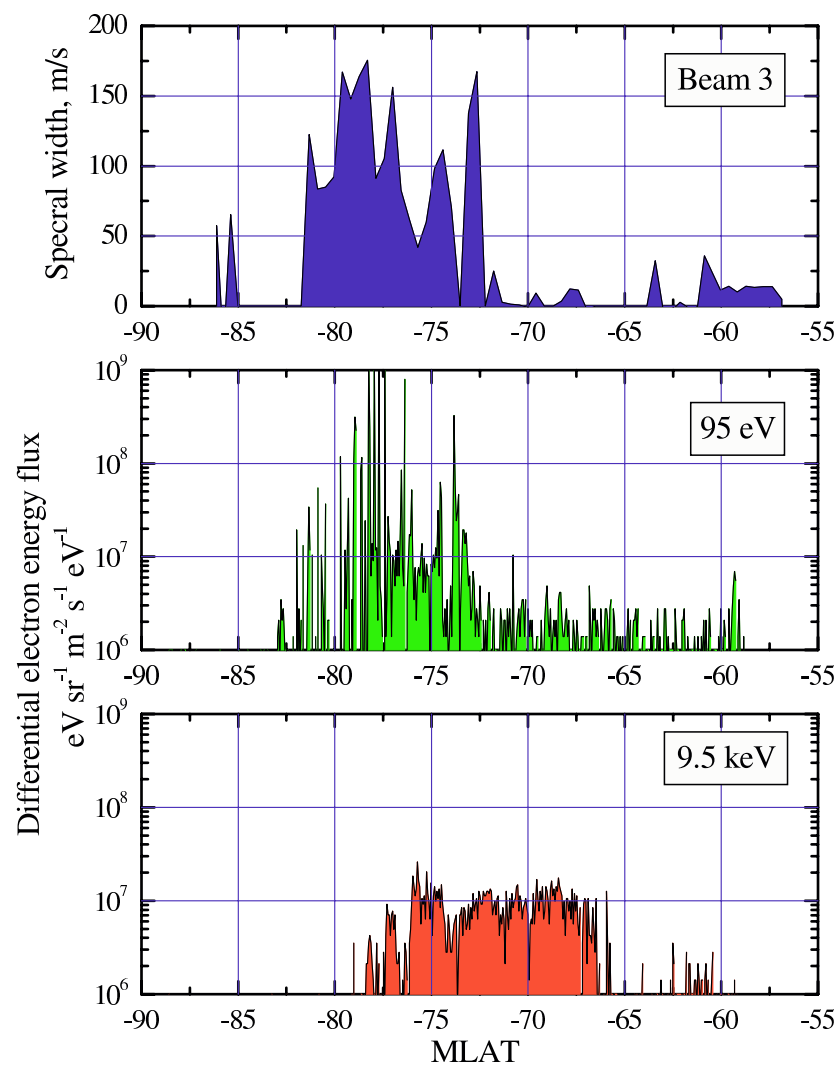

Fig. 12. Time series of DMSP15 differential electron flux and TIGER spectral width (beam 3) for data presented in Fig. 11.

In Sects. 3 and 4, typical values for $W$ provide a lifetime $\tau_{l} \sim 10-25 \mathrm{~ms}$. What is the property of precipitating electrons which causes such variations in the turbulence intensity? We suggest that the key to identifying the physical mechanism involves the contrast between the relatively slowvarying high-energy flux and the "soft" electrons, which continuously exhibit intensive temporal variations with periods $\leq 1$ s, i.e. the DMSP sampling rate. It might be suggested that this is a signature of the electron flux modulating the lifetime of the decameter irregularities with $\tau_{l} \sim 10-25 \mathrm{~ms}$. However, to validate this hypothesis it is necessary to determine if these variations are temporal or spatial and to measure electron flux fluctuations with a sample rate $\sim 1 \mathrm{~ms}$.

Furthermore, in the light of Figs. 11 and 13, the current definition of the SWB may need modification. Indeed, the scope of previous research (e.g. Parkinson et al., 2004; Chisham et al., 2004, 2005a,b, etc) was limited to a boundary between relatively large and small spectral width regions. This has influenced both data processing algorithms and the physical interpretation of the results. However, Fig. 2 clearly shows that the large- $W$ echoes are not necessarily accompanied by small- $W$ values. Moreover, the "real" boundary position might be effectively masked or convincingly imitated 


\author{
Median spectral width $(W)$ \\ 02-06 September 2005 \\ (all beams converted to $f_{0}=11.5 \mathrm{MHz}$ )
}

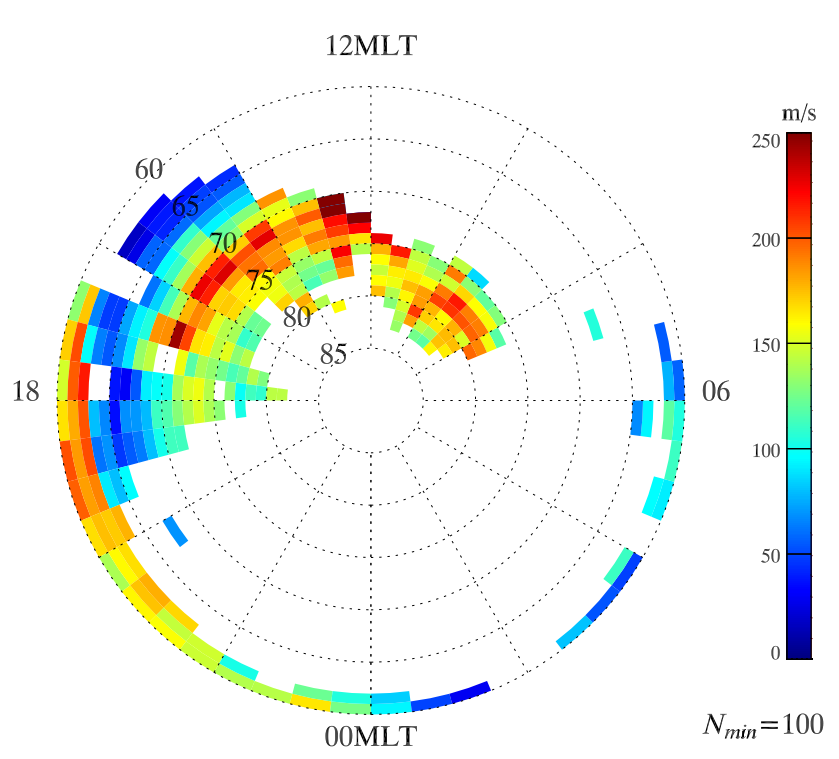

Fig. 13. MLAT-MLT map for median spectral width of TIGER data calculated for 2-6 September 2005 (all data were converted to $f_{0}=11.5 \mathrm{MHz}$ ). Minimum number of data points per bin was $N_{\min }=100$.

by mixed scatter. This can potentially distort statistical studies where the propagation mode cannot be controlled by an experienced operator as in case studies. Therefore, studies of large spectral width areas instead of the SWB might be more physically meaningful.

Finally, while the nature of E-region irregularities lies outside the scope of this work, we would like to point out contradictory results obtained for large- $W$ echoes from this region (Fig. 10). They exhibit a predominantly exponential ACF decay, which suggests that lifetime processes determine their spectral broadening. However, these returns show constant $W[\mathrm{~m} / \mathrm{s}]$ independent on radar frequency, which favours driftrelated broadening mechanisms. This is a topic for future research.

\section{Conclusions}

We have studied the dependence of large spectral width in SuperDARN echoes on radar frequency and its relationship with electron precipitation in different energy bands. Before processing the radar data, we refined the software procedures that identify statistical fluctuations and mixed scatter returns, which has improved data selection.

In agreement with previous findings, the spectral width of high-latitude F-region echoes expressed in velocity units was

\author{
Median differential electron energy flux $(J)$ for $E_{e}=94.9 \mathrm{eV}$ \\ $\left(\mathrm{eV} / \mathrm{sr} \mathrm{m}^{2} \mathrm{~s} \mathrm{eV}\right)$ \\ 02-06 September 2005
}

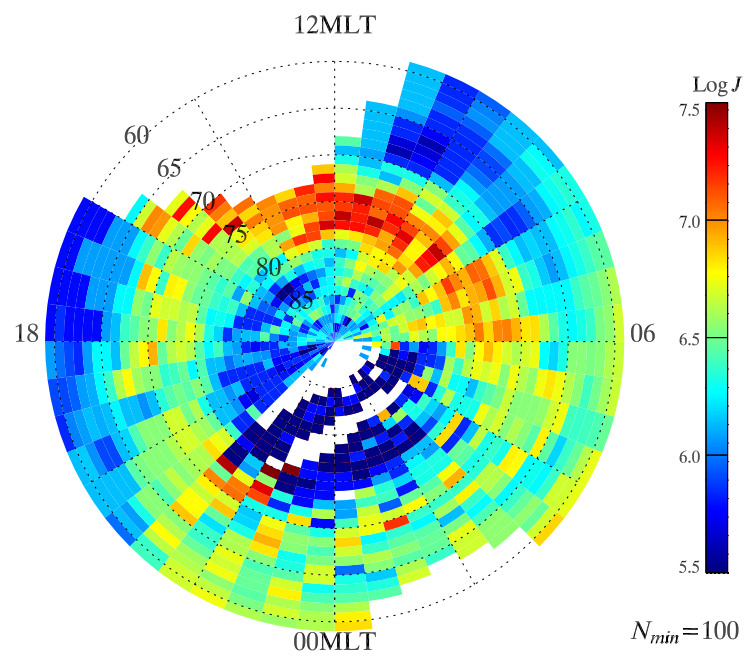

Fig. 14. The same as in Fig. 13 but for DMSP15 differential electron flux at $E_{e}=94.9 \mathrm{eV}$.
Median differential electron energy flux $(J)$ for $E_{e}=9.49 \mathrm{keV}$ $\left(\mathrm{eV} / \mathrm{sr} \mathrm{m}^{2} \mathrm{~s} \mathrm{eV}\right)$
02-06 September 2005

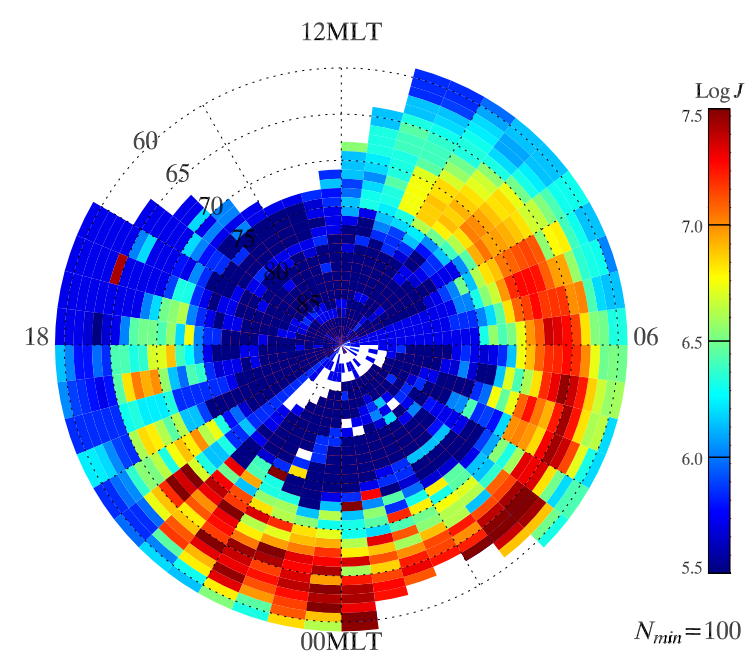

Fig. 15. The same as in Fig. 15 but for $E_{e}=9.49 \mathrm{keV}$.

found to decrease with increasing radar frequency. However, most of the radar returns with $W \geq 100-150 \mathrm{~m} / \mathrm{s}$ are better characterized by an exponential ACF power decay, which argues for a mechanism where the spectral broadening is determined by a finite irregularity lifetime rather than random plasma drifts. This suggests that the spectral width does not 
describe decameter turbulence, and should be replaced by ACF power decay time, $\tau_{c} \simeq(\lambda / 2) / W$ as an estimate of the irregularity lifetime. The median lifetime of the decameter irregularities $\tau_{l} \sim 10-25 \mathrm{~ms}$ appears to be essentially independent of scale size, which argues against plasma diffusion as a major factor limiting $\tau_{l}$. This explains the apparent decrease in $W \simeq \lambda / 2 \tau_{c}$ with increasing radar frequency because it is represented in velocity units and, as a result, inversely proportional to $f_{0}$.

The large- $W\left(\right.$ low- $\left.\tau_{c}\right)$ radar echoes appear to be co-located with "soft" electron precipitation. The $100-\mathrm{eV}$ electron flux exhibits high temporal variability on a time scale equal to or shorter than the instrumental sampling rate $1 \mathrm{~s}$. These variations might be the main cause of the observed $\tau_{l}$ values, if the whole spectrum of plasma irregularities is modulated by the precipitating electrons. However, to check this hypothesis it is necessary to study the spatio-temporal structure of the "soft" precipitation with higher temporal resolution $(\sim 1 \mathrm{~ms})$, which is not easily achievable.

Acknowledgements. This work was supported by the Australian Research Council and the University of Newcastle. We also thank P. Dyson, J. Devlin and M. Parkinson for operating and providing data from the TIGER radar. We would like to thank J. Skura for assisting with DMSP data.

Topical Editor M. Pinnock thanks M. Freeman and K. Baker for their help in evaluating this paper.

\section{References}

André, R., Pinnock, M., Villain, J. P., and Hanuise, C.: On the factor conditioning the Doppler spectral width determined from SuperDARN HF radars, Int. J. Geomagn. Aeron., 2, 77-86, 2000.

Baker, K. B. and Wing, S.: A new magnetic coordinate system for conjugate studies at high latitudes, J. Geophys. Res., 94, 91399144, 1989.

Baker, K. B., Greenwald, R. A., Walker, A. D. M., Bythrow, P. F., Zanetti, L. J., Potemra, T. A., Hardy, D., Rich, F. J., and Rino, C. L.: A case study of plasma processes in the dayside cleft, J. Geophys. Res., 91, 3130-3144, 1986.

Baker, K. B., Greenwald, R. A., Ruohoniemi, J. M., Dudeney, J. R., Pinnock, M., Newell, P. T., Greenspan, M. E., and Meng, C.I.: Simultaneous HF-radar and DMSP observations of the cusp, Geophys. Res. Lett., 17, 1869-1872, 1990.

Baker, K. B., Dudeney, J. R., Greenwald, R. A., Pinnock, M., Newell, P. T., Rodger, A. S., Mattin, N., and Meng, C.-I.: HF radar signatures of the cusp and low-latitude boundary layer, J. Geophys. Res., 100, 7671-7695, 1995.

Chisham, G., Freeman, M. P., and Sotirelis, T.: Statistical comparison of SuperDARN spectral width boundaries and DMSP particle precipitation boundaries in the nightside ionosphere, Geophys. Res. Lett., 31, L02 804, doi:10.1029/2003GL019074, 2004.

Chisham, G., Freeman, M. P., Lam, M. M., Abel, G. A., Sotirelis, T., Greenwald, R. A., and Lester, M.: A statistical comparison of SuperDARN spectral width boundaries and DMSP particle precipitation boundaries in the afternoon sector ionosphere, Ann. Geophys., 23, 3645-3654, 2005a.
Chisham, G., Freeman, M. P., Sotirelis, T., Greenwald, R. A., Lester, M., and Villain, J.-P.: A statistical comparison of SuperDARN spectral width boundaries and DMSP particle precipitation boundaries in the morning sector ionosphere, Ann. Geophys., 23, 733-743, 2005b.

Dudeney, J. R., Rodger, A. S., Freeman, M. P., Pickett, J., Scudder, J., Sofko, G., and Lester, M.: The nightside ionospheric response to IMF $B_{y}$ changes, Geophys. Res. Lett., 25, 2601-2604, 1998.

Greenwald, R. A., Baker, K. B., Hutchins, R. A., and Haniuse, C.: An HF phased-array radar for studying small-scale structure in the high-latitude ionosphere, Radio Sci., 20, 63-79, 1985.

Greenwald, R. A., Baker, K. B., Dudeney, J. R., Pinnock, M., Jones, T. B., Thomas, E. C., Villain, J. P., Cerisier, J. C., Senior, C., Haniuse, C., Hunsucker, R. D., Sofko, G., Koehler, J., Nielsen, E., Pellinen, R., Walker, A. D. M., Sato, N., and Yamagishi, H.: DARN/SuperDARN: A global view of the dynamics of highlatitude convection, Space. Sci. Rev., 71, 761-795, 1995.

Hanuise, M., Villain, J. P., Gresillon, D., Cabrit, B., Greenwald, R. A., and Baker, K. B.: Interpretation of HF radar ionospheric Doppler spectra by collective wave scattering theory, Ann. Geophys., 11, 29-39, 1993, http://www.ann-geophys.net/11/29/1993/.

Lester, M., Milan, S. E., Besser, V., and Smith, R.: A case study of $\mathrm{HF}$ radar spectra and $630.0 \mathrm{~nm}$ auroral emission in the premidnight sector, Ann. Geophys., 18, 327-339, 2001, http://www.ann-geophys.net/18/327/2001/.

Moen, J., Carlson, H. C., Milan, S. E., Shumilov, N., Lybekk, B., Sandholt, P. E., and Lester, M.: On the collocation between dayside auroral activity and coherent HF radar backscatter, Ann. Geophys., 18, 1531-1549, 2001, http://www.ann-geophys.net/18/1531/2001/.

Moen, J., Walker, I. K., Kersley, K., and Milan, S. E.: On the generation of cusp HF backsatter irregularities, J. Geophys. Res., 107(A4), 1044, doi:10.1029/2001JA000111, 2002.

Parkinson, M. L., Chisham, G., Pinnock, M., Dyson, P. L., and Devlin, J. C.: Magnetic local time, substorm, and particle precipitation-related variations in the behaviour of SuperDARN Doppler spectral width, Ann. Geophys., 22, 4103-4122, 2004, http://www.ann-geophys.net/22/4103/2004/.

Ponomarenko, P. V. and Waters, C. L.: The role of Pc1-2 waves in spectral broadening of SuperDARN echoes from high latitudes, Geophys. Res. Lett., 30, L1122, doi:10.1029/2002GL016333, 2003.

Ponomarenko, P. V. and Waters, C. L.: Spectral width of SuperDARN echoes: Measurement, use and physical interpretation, Ann. Geophys., 24, 115-128, 2006, http://www.ann-geophys.net/24/115/2006/.

Rytov, S. M., Kravtsov, Y. A., and Tatarskii, V. I.: Principles of Statistical Radiophysics, Springer-Verlag, New York, 1988.

Vallières, X., Villain, J.-P., and André, R.: Characterization of frequency effect in SuperDARN spectral width distributions, Radio Sci., 38, 1003-1014, doi:10.1029/2001RS002550, 2003.

Vallières, X., Villain, J.-P., Hanuise, C., and André, R.: Ionospheric propagation effects on spectral widths measured by SuperDARN HF radars, Ann. Geophys., 22, 2023-2031, 2004, http://www.ann-geophys.net/22/2023/2004/.

Villain, J.-P., André, R., Hanuise, C., and Gresillon, D.: Observation of the high-latitude ionosphere by HF radars: Interpretation in terms of collectivewave scattering and characterization of the 
turbulence, J. Atmos. Sol. Terr. Phys., 58, 943-958, 1996.

Villain, J.-P., André, R., Pinnock, M., Greenwald, R. A., and Hanuise, C.: A statistical study of the Doppler spectral width of high-latitude ionospheric F-region echoes recorded with SuperDARN coherent HF radars, Ann. Geophys., 20, 1769-1781, 2002, http://www.ann-geophys.net/20/1769/2002/.
Woodfield, E. E., Davies, J. A., Eglitis, P., and Lester, M.: A case study of HF radar spectral width in the post midnight magnetic local time sector and its relationship to the polar cap boundary, Ann. Geophys., 20, 501-509, 2002,

http://www.ann-geophys.net/20/501/2002/. 